\title{
In-Check System: a Highly Integrated Silicon Lab-on-chip for Sample Preparation, PCR Amplification and Microarray Detection Towards the Molecular Diagnostics Point-of-care
}

\author{
S. Petralia' ${ }^{1}$, E. Alessi', M. G. Amore ${ }^{1}$, Claudio Schneider ${ }^{2}$,Enio Klaric ${ }^{2}$, Roberto Verardo ${ }^{2}$ \\ ${ }^{1}$ Molecular Diagnostics Business Unit R\&D STMicroelectronics Stradale Primosole 50 - 95121 catania \\ (Italy) tel +390957404388 (2566) fax +390957403031 \\ corresponding e-mail address: salvatore.petralia@st.com \\ ${ }^{2}$ LNCIB Area Science Park Padriciano 9934149 - Trieste Italy Tel. +39-0403756804
}

\begin{abstract}
:
The In-Check System is based on a miniaturized silicon lab-on-chip (LoC) where the Polymerase Chain reactor lives together with a customizable microarray module for running a seamless nucleic acid test [1]. This device is designed for accurate temperature performances control, such as accuracy and heating rate provided by both a sophisticated chip calibration process and a precise control by the Temperature Control System (TCS). In addition, the device, is optimized for a microarray fluorescence reading operation by an external instrument, the optical reader (OR). Finally, it is based on microfluidic features that enable to load the chip and fill the reaction chambers without the risk of bubble formation or leaks.

In this manuscript are reported the experimental results for the detection of human betaglobine gene (HBB) directly from human cells in less than 2 hours in a silicon reactor. The sample preparation process was entirely performed in one single step into the silicon reactor. It was fully characterized by RT-qPCR. We performed also a comparison study showing higher performances in the LoC silicon reactor than the standard tube. Moreover, the DNA extracted was amplified by PCR, and the resulting product hybridized on the microarray. All the results suggest that the hybridization reactions performed on the silicon LoC can be used to exploit the discriminatory power of microarrays for a specific gene detection.
\end{abstract}

Key words: Lab-onChip, PCR, sample preparation, microarray, DNA.

\section{In-Check system}

The development of a simple and rapid point-ofcare diagnostic platform is essential for the evolution of sensing for healthcare technologies [2]. This work represents a first step towards the integration of a sample preparation reaction into a silicon reactor and thus enabling the whole seamless process of sample prep, PCR amplification and microarray hybridization in a single disposable device [3-5]. These promising results open the potential to extend ST InCheck System to a full test from sample in to answer out.
In-Check system developed by STMicroelectronics (Italy) is an open platform for fast and automated nucleic acid identification. In this context In-Check combines the power of PCR amplification with the multianalytical capability of microarray, and the ability to perform the sample preparation in one step without further purification phases. The InCheck system reported in figure 1 is comprised of a miniaturized silicon chip (LoC) assembled in a standard PCB: a temperature control system, (TCS) an optical reader and the software platform. 


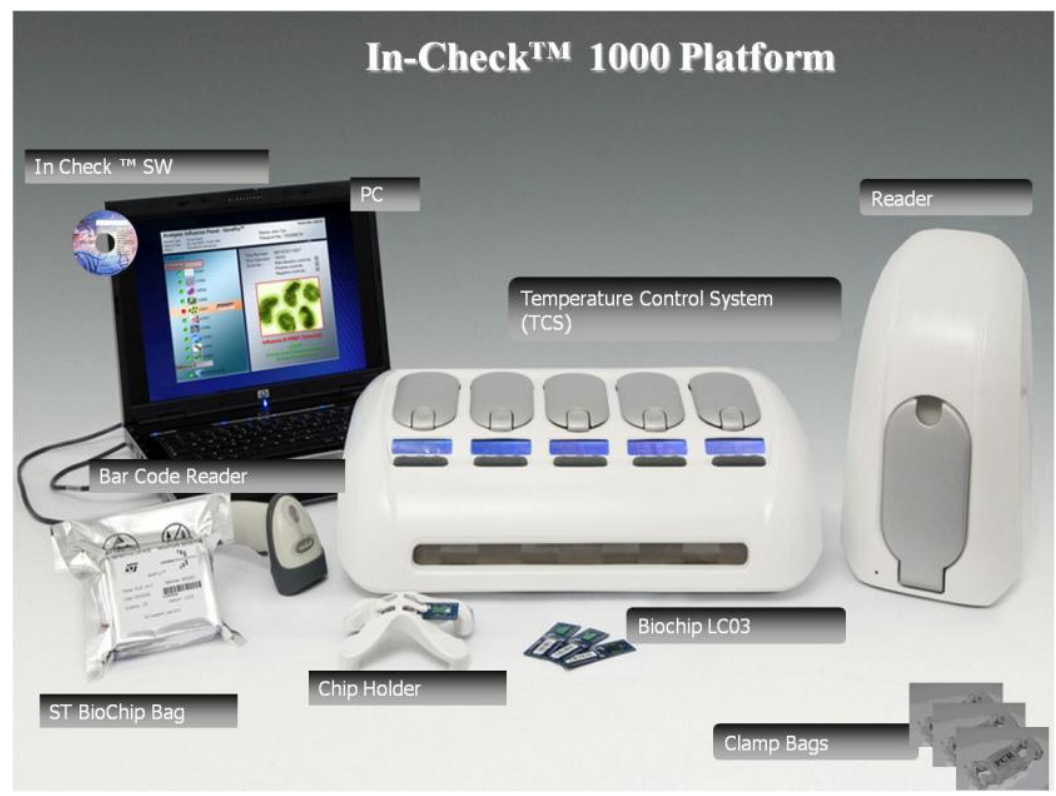

Fig. 1 In-Check system composition

\section{In-Check: sample preparation-PCR- hybridization integrated test.}

The Lab-on-Chip is a silicon based device, manufactured by MEMS technology, bonded with dry resist glue togheter with a silicon wafer cap and mounted ona a 1"x3" PCB support that provides mechanical, thermal, and electrical connection.

The LoC is composed by two silicon microreactors fluidically connected to a mycroarray chamber. Each silicon microreactor (maximum volume of $12 \mathrm{ul}$ ) contains resistors and sensors at different position for thermal process (scheme 1).

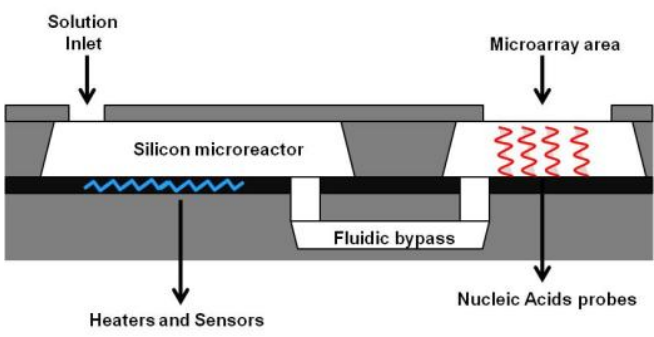

Scheme 1 Lab-on-Chip sheme

The LoC integrated, within the same device, the sample preparation process and the DNA amplification together with a microarray for the detection of the Cy5 dye fluorescence intensity. In figure 3 is reported the In-Check fully integrated process from sample to answer information, for the detection of nucleic acid from human cells.

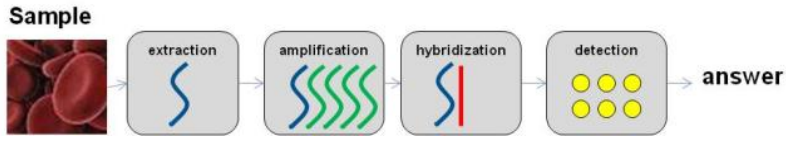

Fig. 2 In-Check full-integrated process from sample to answer

Sample preparation process: In order to evaluate the performance of the sample preparation module DNA extraction process was performed by means of a mix composed by a different amounts of SKOV3 cultured human cells $(10000,5000$ and 1000 cells). For comparison, the same study was performed on LoC and on standard PCR tube. The DNA extraction efficiency was evaluated by real-time RT-PCR, with SYBR Green detection, on a StepOnePlus Real-Time PCR System (Applied Biosystems). Amplification specificities were evaluated by analyzing the melting curves of the resulting amplicons.

Figure 3 shows the relative fold changes of the amplification signals for the DNA extracted from the different amounts of cells, in tube and in the LoC system as compared to the amplification of the DNA extracted using a competitor (QIAGEN). 


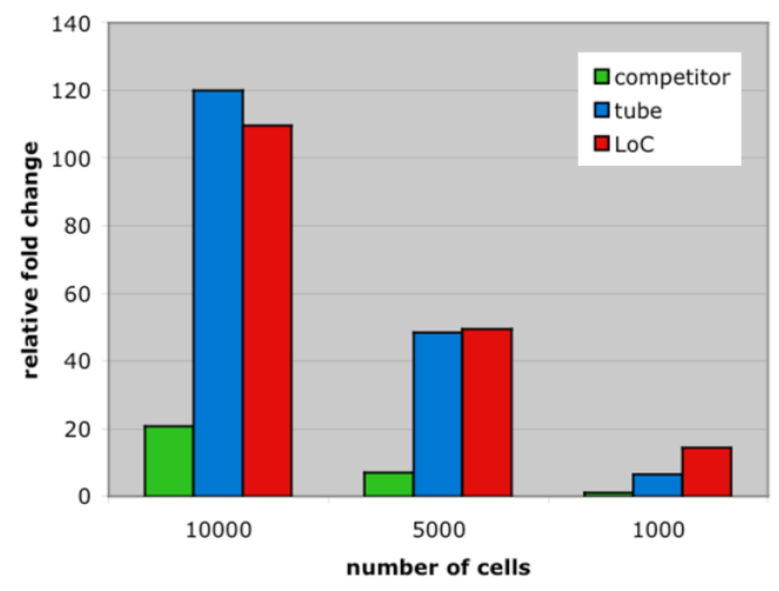

Fig. 2. qRt-PCR signal for the DNA extracted in LoC, standard tube and in tube by QIAGEN (competitor).

\section{Integrated PCR and Microarray Hybridization.}

The HBB-gene, by extracted DNA, was amplified by PCR on microarray chamber and the amplicon detected on ssDNA microarray.

In figure 5 is reported an example of fluorescence hybridized microarray image for the full-integrated process: sample preparationPCR-hybridization performed by In-Check system.
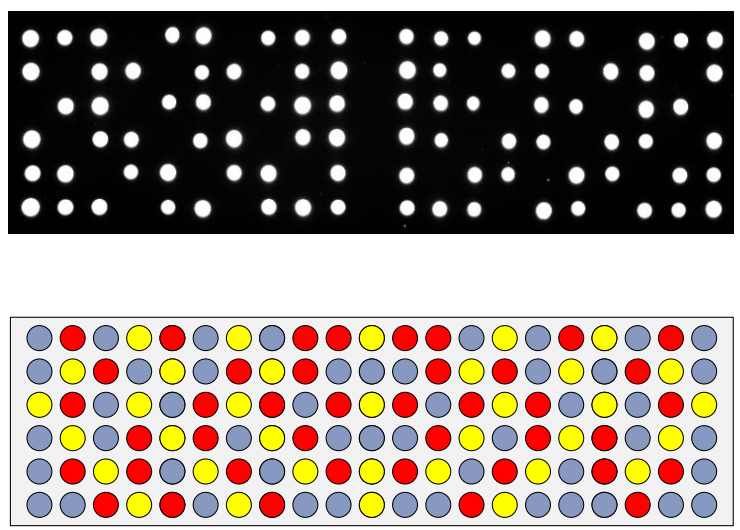

Hybridization contro
HBB capture probe

Background control

Fig. 3. Hybridized Microarray image and microarray layout.

\section{Conclusion}

This study reported the application of In-Check system for the detection of HBB-gene directly on human cells. The In-Check system performed the sample preparation, PCR and hybridization detection in one chip and in less than two hours without further purification, concentration and separation steps.

\section{References}

[1] B. Foglieni, A. Brisci, F. San Biagio, P. Di Pietro, S. Petralia, S. Conoci, M. Ferrari, L. Cremonesi, Clin Chem Lab Med;48(3), 329-336 (2010); DOI: 10,1515/CCLM.2010.063

[2] Chen X, Cui da F., Liu CC On-line cell lysis and $\mathrm{DNa}$ extraction on a microfluidics biochip fabricated by microelectromechanical system technology Electrophoresis 29,1844-51 (2008)

[3] Hearps A, Zhang Z, Alexandersen S. Evaluation of the portable Cepheid SmartCycler real-time PCR machine for the rapid diagnosis of foot-andmouth disease. Vet Rec 150(20), 625-8 (2002).

[4] Consolandi C, Severgnini M, Frosini A, Caramenti G, De Fazio M, Ferrara F, Zocco A, Fischetti A, Palmieri M, De Bellis G. Polymerase chain reaction of $2-k b$ cyanobacterial gene and human anti-alpha1-hymotrypsin gene from genomic DNA on the In-Check single-use microfabricated silicon chip. Anal Biochem 353(2), 191-7 (2006).

[5] Zhang C, Xu J, Ma W, Zheng W. PCR microfluidic devices for DNA amplification. Biotechnol Adv 24(3), 243-84 (2006). 